\title{
Blood Transfusion Strategies in Patients Supported by Extracorporeal Membrane Oxygenation
}

\author{
Yoon Hee Kim, M.D., Ph.D. \\ Department of Anesthesiology and Pain Medicine, Chungnam University Medical School, Daejeon, Korea
}

Since red blood cell (RBC) transfusion was first performed by English obstetrician James Blundell 200 years ago,[1] it has become one of the most commonly used lifesaving therapies. Historically, RBC transfusion have been viewed as a safe and effective means of treating anemia and improving oxygen delivery to tissues. However, in the early $1980 \mathrm{~s}$, transfusion practice began to come under systematic scrutiny.[2,3] The early concern about the safety of blood transfusion revolved around transfusion-related infection. However, the concern about risks of blood transfusion have become diverse and complicated over the last three decades, according to research findings.

In the recent literature, blood transfusion has been confirmed as an independent risk factor for mortality, perioperative infection, postinjury multiple organ failure, systemic inflammatory response syndrome, and admission to the intensive care unit(ICU).[4-7] Problems about blood transfusion are particularly important in the critically ill patients.

Many data suggest that critically ill patients can tolerate hemoglobin levels as low as $7 \mathrm{~g} / \mathrm{dL}$ and that a "liberal" RBC transfusion strategy may in fact lead to worse clinical outcomes.[8] Actually, RBC transfusion impairs physiologic control of regional vascular tone, induces coagulopathy and negatively impacts immune function and antioxidant system.[9]

The 2012 Cochrane analysis reported that restrictive transfusion strategies were more effective than liberal transfusion strategies in reducing hospital mortality significantly among 6,264 patients from 1986 to 2011.[10,11] As such, newer "restrictive" hematocrit threshold for transfusion (e.g., 21\%) are now appreciated to be at least noninferior to more "liberal" hematocrit thresholds (e.g., 30\%) for broad array of conditions.[9]

The efficacy of transfusion in critically ill pediatric patients has been also questioned as is still uncertain for adult critically ill patients. Lacroix et al. suggested, based on their TRIPICU study, that there was no difference in outcomes of stable critically ill children between restrictive (hemoglobin threshold of $7 \mathrm{~g} / \mathrm{dL}$ ) and liberal (hemoglobin threshold of $9.5 \mathrm{~g} / \mathrm{dL}$ ) transfusion strategies.[12]

Subgroup analysis of postsurgical and postcardiac surgical patients from the TRIPICU study revealed similar findings. Among pediatric cardiac surgical patients, greater $\mathrm{RBC}$ transfusion volumes are associated with prolonged duration of mechanical ventilation, an increase in nosocomial infection rates and duration of hospitalization.[13,14]

\section{Yoon Hee Kim}

Department of Anesthesiology and Pain Medicine, Chungnam University Medical School, Chungnam University Hospital,

282 Munhwa-ro, Jung-gu, Daejeon

35015, Korea

Tel: +82-42-280-7840

Fax: +82-42-280-7968

E-mail: yhkim0404@cnu.ac.kr

\section{ORCID}

Yoon Hee Kim

http://orcid.org/0000-0002-8282-610X

*No potential conflict of interest relevant to this article was reported. 
The discovered association between RBC transfusion volume and morbidity in critically ill patients has promoted the reevaluation of transfusion strategies used for ECMO patients.

ECMO use has been associated with transfusion of large volumes of RBCs and with exposure to a large number of donor RBC units.[15] Diverse hemostatic strategies are presently used during ECMO such as use of a smaller circuit, antifibrinolytic agents and heparin coated circuits. However numerous RBC transfusion are still requested for circuit priming and due to bleeding, coagulopathy and hemolysis during ECMO course.

Although RBC transfusion are performed by bleeding complications, many RBC transfusions are ordered for the purpose of maintaining an arbitrary hemoglobin threshold in these patients. There is no accepted RBC transfusion threshold for patients supported with ECMO. Guidelines published by the Extracorporeal Life Support Organization call for maintenance of a normal hematocrit and define anemia as a hematocrit less than $45 \%$.[16] Others have used hematocrit threshold between $35 \%$ and $45 \%$.[17,18] There are no published prospective data describing the utility and safety of restrictive transfusion strategy among patients receiving ECMO.However, several observational trials in patients with ECMO have suggested that more RBC transfusions related to worse outcomes in some patients. Smith et al. [17] reported that greater RBC transfusion volumes among pediatric patients supported with ECMO for non-cardiac indications are independently associated with an increase in odds of mortality. Kumar et al.[18] concluded that exposure to high amounts of blood transfusion while on ECMO increase the risk of death in patients even after successful decannulation. At present, there are no evidence suggesting that a higher hemoglobin is beneficial to patients supported with ECMO. Fisher et al.[19] retrospectively evaluated the efficacy of RBC transfusion on tissue oxygenation in 45 children with ECMO. They reported that RBC transfusion did not significantly improve global tissue oxygenation, as assessed by changes in mixed venous oxygen saturation and cerebral near infrared spectroscopy. $\mathrm{RBC}$ transfusion is indicated to improve oxygen delivery to tissue and for no other purpose. The trial reported by Fisher et al. states that increased blood oxygen content as a result of RBC transfusion does not always guarantee the increase in oxygen delivery to the tissues. It is true that some researchers are also skeptical about the impacts of transfusion on oxygen delivery. The stored blood is depleted of 2,3-diphosphoglycerate (2, 3-DPG), and adenosine triphosphate. Depletion of 2, 3-DPG results in an increased affinity of hemoglobin for oxygen and impairs the release of oxygen to the tissue. Depletion of adenosine triphosphate results in both altered deformability and loss of integrity of the RBC membrane, which in turn can negatively impact microvascular flow and lead to early destruction of transfused RBCs. Also small quantities of free hemoglobin of transfused blood act as scavengers of nitric oxide, perhaps resulting in microvessel vasoconstriction and thus reducing local tissue oxygen delivery.[2025] In both critically ill adults and pediatric patients, age of stored RBCs are associated with worse tissue oxygenation and organ dysfunction.[26-28] As far as storage lesion is concerned, the rapid massive leakage of potassium from weak RBC membrane into the extracellular space can cause sudden cardiac arrest.[29] Such an adverse effect of stored $\mathrm{RBC}$ transfusion on oxygen delivery and worse outcomes in transfused patients underscore the need for reconsideration or resetting of the traditional transfusion thresholds in ECMO patients. Additional studies are needed to establish the appropriate $\mathrm{RBC}$ transfusion threshold for patients supported with ECMO. deally, ECMO patients would be better off with transfusion strategies that can improve oxygen delivery by addressing patient variables and stress-specific situations instead of hematocrit trigger strategies.

\section{References}

1) Remy KE, Natanson C, Klein HG: The influence of the storage lesion(s) on pediatric red cell transfusion. Curr Opin Pediatr 2015; 27: 277-85.

2) Consensusconference. Perioperativered blood cell transfusion. JAMA 1988; 260: 2700-3.

3) Welch HG, Meehan KR, Goodnough LT: Prudent strategies for elective red blood cell transfusion. Ann Intern Med 1992; 116: 393-402.

4) Carson JL, Altman DG, Duff A, Noveck H, Weinstein MP, Sonnenberg FA, et al: Risk of bacterial infection associated with allogeneic blood transfusion among patients undergoing hip fracture repair. Transfusion 1999; 39: 694-700. 
5) Taylor RW, Manganaro L, O’Brien J, Trottier SJ, Parkar $\mathrm{N}$, Veremakis $\mathrm{C}$ : Impact of allogenic packed red blood cell transfusion on nosocomial infection rates in the critically ill patient. Crit Care Med 2002; 30: 2249-54.

6) Claridge JA, Sawyer RG, Schulman AM, McLemore EC, Young JS: Blood transfusions correlate with infections in trauma patients in a dose-dependent manner. Am Surg 2002; 68: 566-72.

7) Moore FA, Moore EE, Sauaia A: Blood transfusion. An independent risk factor for postinjury multiple organ failure. Arch Surg 1997; 132: 620-4; discussion 624-5.

8) Groeger JS, Guntupalli KK, Strosberg M, Halpern N, Raphaely RC, Cerra F, et al: Descriptive analysis of critical care units in the United States: patient characteristics and intensive care unit utilization. Crit Care Med 1993; 21: 279-91.

9) Villanueva C, Colomo A, Bosch A, Concepción M, Hernandez-Gea V, Aracil C, et al: Transfusion strategies for acute upper gastrointestinal bleeding. N Engl J Med 2013; 368: 11-21.

10) Carson JL, Carless PA, Hebert PC: Transfusion thresholds and other strategies for guiding allogeneic red blood cell transfusion. Cochrane Database Syst Rev 2012 Apr 18; 4: CD002042.

11) Carson JL, Carless PA, Hébert PC: Outcomes using lower vs higher hemoglobin thresholds for red blood cell transfusion. JAMA 2013; 309: 83-4.

12) Lacroix J, Hébert PC, Hutchison JS, Hume HA, Tucci M, Ducruet T, et al: Transfusion strategies for patients in pediatric intensive care units. N Engl J Med 2007; 356: 1609-19.

13) Rouette J, Trottier H, Ducruet T, Beaunoyer M, Lacroix J, Tucci M, et al. Red blood cell transfusion threshold in postsurgical pediatric intensive care patients: a randomized clinical trial. Ann Surg 2010; 251: 421-7.

14) Willems A, Harrington $K$, Lacroix J, Biarent D, Joffe AR, Wensley D, et al: Comparison of two red-cell transfusion strategies after pediatric cardiac surgery: a subgroup analysis. Crit Care Med 2010; 38: 649-56.

15) Butch SH, Knafl P, Oberman HA, Bartlett RH: Blood utilization in adult patients undergoing extracorporeal membrane oxygenated therapy. Transfusion 1996; 36: 61-3.

16) Extracorporeal Life Support Organization: General
Guidelines for All ECLS Cases. 2013. Accessed July 6, 2014.

17) Smith A, Hardison D, Bridges B, Pietsch J: Red blood cell transfusion volume and mortality among patients receiving extracorporeal membrane oxygenation. Perfusion 2013; 28: 54-60.

18) Kumar TK, Zurakowski D, Dalton H, Talwar S, AllardPicou A, Duebener LF, et al: Extracorporeal membrane oxygenation in postcardiotomy patients: factors influencing outcome. J Thorac Cardiovasc Surg 2010; 140: 330-36.e2

19) Fiser RT, Irby K, Ward RM, Tang X, McKamie W, Prodhan $\mathrm{P}$, et al: RBC transfusion in pediatricpatientssupported with extracorporeal membrane oxygenation: is there an impact on tissue oxygenation? Pediatr Crit Care Med 2014; 15: 806-13.

20) Klein HG, Spahn DR, Carson JL: Red blood cell transfusion in clinical practice. Lancet 2007; 370: 415-26.

21) Luten M, Roerdinkholder-Stoelwinder B, Schaap NP, de Grip WJ, Bos HJ, Bosman GJ: Survival of red blood cells after transfusion: a comparison between red cells concentrates of different storage periods. Transfusion 2008; 48: 1478-85.

22) Bosman GJ, Werre JM, Willekens FL, Novotný VM: Erythrocyte ageing in vivo and in vitro: structural aspects and implications for transfusion. Transfus Med 2008; 18: 335-47.

23) Tinmouth A, Fergusson D, Yee IC, Hébert PC, ABLE Investigators, Canadian Critical Care Trials Group: Clinical consequences of red cell storage in the critically ill. Transfusion 2006; 46: 2014-27.

24) Doctor A, Platt R, Sheram ML, Eischeid A, McMahon T, Maxey T, et al: Hemoglobin conformation couples erythrocyte S-nitrosothiol content to $\mathrm{O} 2$ gradients. Proc Natl Acad Sci U S A 2005; 102: 5709-14.

25) Reiter CD, Wang X, Tanus-Santos JE, Hogg N, Cannon RO 3rd, Schechter AN, et al: Cell-free hemoglobin limits nitric oxide bioavailability in sickle-cell disease. Nat Med 2002; 8: 1383-9.

26) Marik PE, Sibbald WJ: Effect of stored-blood transfusion on oxygen delivery in patients with sepsis. JAMA 1993; 269: 3024-9.

27) Karam O, Tucci M, Bateman ST, Ducruet T, Spinella PC, Randolph AG, et al: Association between length of 
storage of red blood cell units and outcome of critically ill children: a prospective observational study. Crit Care 2010; 14: R57.

28) Gauvin F, Spinella PC, Lacroix J, Choker G, Ducruet T, Karam O, et al: Association between length of storage of transfused red blood cells and multiple organ dysfunction syndrome in pediatric intensive care patients.
Transfusion 2010; 50: 1902-13.

29) Kim DW, Cheon KR, Cho D, Lee KS, Cho HJ, Jeong IS: Transfusion associated hyperkalemia and cardiac arrest in an infant after extracorporeal membrane oxygenation. Korean J Crit Care Med 2015; 30: 132-4. 